\title{
Regulation of Cation Transport by Low Doses of Glucocorticoids in In Vivo Adrenalectomized Rat Colon
}

Christine P. Bastl

With the technical assistance of Veena Kapoor

Section of Nephrology, Department of Medicine, Temple University Health Sciences Center, Philadelphia, Pennsylvania 19140

\begin{abstract}
A dose response curve for glucocorticoid-induced proximal and distal colonic cation transport in vivo was established in adrenalectomized rats. All doses (0.5-50 nmol/100 g body wt) stimulated sodium absorption. Distal sodium absorption did not saturate at dexamethasone levels that saturate the glucocorticoid receptor but also bind to $>35 \%$ of aldosterone receptors. Saturation of the pure glucocorticoid response occurred in both segments with RU26988, a synthetic glucocorticoid that does not occupy aldosterone receptors. Maximum velocities for pure glucocorticoid-induced sodium absorption were 15 and $16 \mu \mathrm{eq} / \mathrm{min}$ per $g$ dry tissue, and Michaelis constants $\left(K_{m}\right)$ were 4.2 and 4.6 $\times 10^{-9} \mathrm{~mol} / \mathrm{liter}$ for proximal and distal colon. $K_{\mathrm{m}} \mathrm{s}$ are similar to the dissociation constant for the colonic glucocorticoid receptor and too low for significant aldosterone receptor occupancy. Dexamethasone increased sodium absorption significantly within $30 \mathrm{~min}$ of injection, suggesting the response is not dependent on new protein synthesis. Similar time and dose responses in proximal and distal colon suggest glucocorticoids stimulate the same pathway in both segments.
\end{abstract}

\section{Introduction}

We demonstrated that small doses of glucocorticoids were more effective than higher doses of aldosterone in restoring cation transport to normal basal rates in adrenalectomized rats (1). Subsequently, most of the in vivo and in vitro studies of glucocorticoid-induced colon transport have used amounts of glucocorticoids that could permit stimulation of both glucocorticoidand aldosterone-induced pathways (2-9). Thus, the in vivo response of the colon to circulating physiologic levels of glucocorticoids has not been thoroughly investigated.

The entire colon possesses both glucocorticoid and aldosterone receptors, although the number of aldosterone receptors is much greater in the most distal colon than in more proximal segments $(10-13)$. It is possible that both proximal and distal colon are aldosterone-responsive tissues. However, the response to aldosterone is different in the two segments with only the distal colon typically developing significant amiloride-sensitive conductive sodium absorption $(2,8,14-16)$. The colonic response to glucocorticoids has varied with the levels of glucocor-

Address correspondence to Christine P. Bastl, M.D., Section of Nephrology, Temple University Health Sciences Center, 3401 North Broad Street, Philadelphia, PA 19140.

Received for publication 11 October 1985 and in revised form 8 January 1987.

J. Clin. Invest.

(c) The American Society for Clinical Investigation, Inc.

0021-9738/87/08/0348/09 \$2.00

Volume 80, August 1987, 348-356 ticoids used. At levels that approach receptor saturation, glucocorticoid-induced distal colon sodium absorption is amiloride resistant, but at supersaturating levels sodium absorption is amiloride inhibitable $(2,3,5,7-9,16-18)$. Although amiloridesensitive sodium absorption may be induced by crossover binding to aldosterone receptors, important differences have been found between glucocorticoid- and aldosterone-induced transport even with massive doses of glucocorticoids $(2,4-9,13$, 17, 18).

Normally, the rat colon does not demonstrate significant amiloride-inhibitable sodium absorption, probably because circulating aldosterone levels are low $(2,5,7,8,16)$. The normal rat colon has significant amiloride-resistant net sodium absorption which decreases markedly with adrenalectomy $(1,2,5,15$, 16, 19-22). This adrenal dependent sodium absorption could be under the control of circulating physiologic levels of glucocorticoid.

This study examines the effect of two synthetic glucocorticoids, dexamethasone and $11 \beta, 17 \beta$-dihydroxy-17 $\alpha$-propynalandrosta-1,4,6-triene-3-one (RU26988), ${ }^{1}$ on colonic transport in adrenalectomized rats to determine if transport responses are demonstrable within a dose range that would correspond with occupancy of the colonic glucocorticoid receptor.

\section{Methods}

Male Sprague-Dawley rats weighing 250-300 g were adrenalectomized via flank incisions using light ether anesthesia. Rats were immediately begun on steroids in the doses indicated below. The last dose was given $2 \mathrm{~h}$ before colonic flux measurements (three doses total). Rats were maintained on $0.45 \%$ saline containing $2.5 \%$ dextrose but were not fed. One group of adrenalectomized rats was given no steroid replacement. To examine the dose response to dexamethasone, other groups (seven to ten rats per group) were given twice daily subcutaneous doses of 0.5 , $1,2.5,5,10$, and $50 \mathrm{nmol} / 100 \mathrm{~g}$ body wt. The $10 \mathrm{nmol} / 100 \mathrm{~g}$ body weight twice-daily dose has been demonstrated to markedly increase cation transport in adrenalectomized rat colon (1). To determine the maximal colonic response to glucocorticoid in the absence of crossover binding to the aldosterone receptor, we gave adrenalectomized rats RU26988 (Roussel UCLAF, France), a highly specific synthetic glucocorticoid with virtually no binding to the aldosterone receptor or to plasma corticosterone-binding globulin $(23,24)$. The steroid was administered in twice-daily doses of $5,15,30$, and $60 \mathrm{nmol} / 100 \mathrm{~g}$ body wt. Because RU26988's affinity for the glucocorticoid receptor is as high or higher than that of dexamethasone, the higher doses should saturate the glucocorticoid receptor (23-25). We have demonstrated that this steroid has potent agonist activities in colon (10).

To characterize the time course of the transport response, net transport was measured in adrenalectomized rats. $10 \mathrm{nmol}$ of dexamethasone was

1. Abbreviations used in this paper: $B_{\max }$, receptor number; Isc, shortcircuit current; $J_{\mathrm{Na}_{2}} \max$, maximum sodium absorption; PD, potential difference; RU26988, 11 $\beta, 17 \beta$-dihydroxy-17 $\alpha$-propynalandrosta-1,4,6triene-3-one. 
then injected intravenously and transport was measured for an additional six 30-min periods.

24-26 $\mathrm{h}$ after adrenalectomy, in vivo perfusion of the colon was performed. Rats were anesthetized with Inactin (Promonta, Hamburg, FRG), $80 \mathrm{mg} / \mathrm{kg}$. A tracheostomy and jugular venous catheter were inserted. Proximal colon was isolated and cannulated at the cecal colonic junction, distal colon at the insertion of the inferior mesenteric artery, and segments flushed with Ringer's saline until clear. Distal collection catheters were secured at the distal end of the proximal segment and anus. For determination of transmural potential difference (PD), agar bridges were placed in the midportion of the proximal colon and 4-6 $\mathrm{cm}$ from the anus at the point of maximum transmural PD. The reference bridge was placed in the abdominal cavity. Surgical losses were replaced intravenously with $1 \%$ body weight as normal saline and the infusion continued at $0.02 \mathrm{ml} / \mathrm{min}$. Colon segments were perfused with a Holter pump 907 (Critikon Inc., Tampa, FL) at $0.25 \mathrm{ml} / \mathrm{min}$ with a solution containing in meq/liter: $\mathrm{Na}, 140 ; \mathrm{K}, 5 ; \mathrm{Cl}, 115$; and $\mathrm{HCO}_{3}, 25$. $\left[{ }^{14} \mathrm{C}\right]$ polyethylene glycol with unlabeled polyethylene glycol was added as a nonabsorbable water marker at a concentration of $\sim 8,000 \mathrm{cpm} /$ $\mathrm{ml}$. After $1 \mathrm{~h}$ of equilibration, colonic perfusate was collected for five 20-min periods (120-220 min after steroid injection). Transmural PD was measured every $10 \mathrm{~min}$ by the agar bridges connected to calomel electrodes using an Electrometer $610 \mathrm{C}$ (Keithley Instruments, Inc., Cleveland, $\mathrm{OH}$ ).

To determine the adequacy of adrenalectomy, aortic blood was drawn from 25 adrenalectomized glucocorticoid-replaced animals at the end of the colonic perfusion study, centrifuged immediately and the plasma stored at $-70^{\circ} \mathrm{C}$ until plasma aldosterone levels were determined by radioimmunoassay (Diagnostic Products Corp., Los Angeles, CA). The mean poststudy level of aldosterone was below levels of detectability $(<0)$. Only four animals had detectable levels, $3.8 \pm 0.9 \mathrm{ng} / \mathrm{dl}$, and each of these had received the $50-\mathrm{nmol}$ dose of dexamethasone. The plasma level of dexamethasone in this group is within the range where crossreactivity would be expected. In comparison, intact animals have reported aldosterone values of $63-91 \mathrm{ng} / \mathrm{dl}$ after abdominal surgery (26).

Plasma dexamethasone levels obtained during the experimental period were estimated in separate groups of rats adrenalectomized and treated with steroid (3-4 rats/dose) as in the dose-response protocol. Rats were injected subcutaneously with the dexamethasone dose containing tracer amounts of $\left[{ }^{3} \mathrm{H}\right]$ dexamethasone (New England Nuclear, Boston, MA) just before anesthesia. A tracheal tube, carotid, and jugular catheters were placed and surgical losses replaced as previously described. Heparinized blood was drawn at $0.5,1,2,3$, and $4 \mathrm{~h}$ after steroid injection. Abdominal surgery in these animals was performed at $1 \mathrm{~h}$ to correspond with the timing of surgery in the perfusion studies. After centrifugation radioactivity of duplicate plasma samples was determined by liquid scintillation counting. Red cells were resuspended in an equivalent volume of saline and reinfused.

Sodium and potassium concentrations were measured by flame photometer. Duplicate 1-ml samples of perfusate and effluent were counted in Bray's solution in a liquid scintillation counter. Average water, sodium, and potassium fluxes for each animal were calculated by standard formulae and the values expressed as microliters or microequivalents net flux per gram dry tissue (1).

Results for each group are expressed as mean \pm SEM. Intergroup comparisons were made by analysis of variance for unequal subclass numbers. The method of weighted squares of means was used when interactions were present. Statistical significance was set at $P<0.05$. The occupancy of glucocorticoid receptor sites $(R)$ was calculated as described by others $(27-30): R=\left(B_{\max } \times[G]\right) /\left([G]+K_{d}\right)$. Fractional occupancy was calculated by $R / B_{\max }$, where $B_{\max }=$ maximal binding capacity, $[G]=$ plasma concentration of glucocorticoid, and dissociation constant $\left(K_{d}\right)=$ glucocorticoid receptor dissociation constant. To estimate glucocorticoid binding to the aldosterone receptor, the binding constant was calculated from $K_{\mathrm{d}_{\mathrm{c}}}=C_{\mathrm{s0}}\left(K_{\mathrm{d}} / K_{\mathrm{d}}+[\mathrm{S}]\right)$, where $C_{\mathrm{s0}}$ is concentration of glucocorticoid required for $50 \%$ inhibition of aldosterone binding, [S] is concentration of aldosterone at which the competitive binding assay was done, and $K_{d}$ is $K_{d}$ for the aldosterone receptor. Values used were previously determined in this laboratory for proximal and distal colon of adrenalectomized rats $(10,11)$.

\section{Results}

Effect of adrenalectomy on colonic transport. As previously described $(1,19,22,31)$, adrenalectomy markedly depressed the rate of sodium absorption in proximal colon (Fig. 1). The value of $1.4 \pm 1.3 \mu \mathrm{eq} / \mathrm{min}$ per $\mathrm{g}$ dry tissue was not different from zero. In proximal colon, there was actual water secretion of $25 \pm 6.4$ $\mu \mathrm{l} / \mathrm{min}$ per $\mathrm{g}$ dry tissue. Transmural $\mathrm{PD}$ was decreased to $1.6 \pm 0.43 \mathrm{mV}$, lumen negative. Potassium was still secreted at a rate of $0.86 \pm 0.10 \mu \mathrm{eq} / \mathrm{min}$ per $\mathrm{g}$ dry tissue, a value similar to that found in intact controls.

In distal colon, adrenalectomy was associated with a rate of sodium absorption of $1.9 \pm 1.0 \mu \mathrm{eq} / \mathrm{min}$ per $\mathrm{g}$ dry tissue (Fig. 2). Net water flux was $-3.7 \pm 4.8 \mu \mathrm{eq} / \mathrm{min}$ per $\mathrm{g}$ dry tissue. Neither of these values was different from zero. Transmural PD was $8.9 \pm 1.3 \mathrm{mV}$, lumen negative, a value approximately half that previously found in intact controls. Potassium secretion of $1.1 \pm 0.1 \mu \mathrm{eq} / \mathrm{min}$ per $\mathrm{g}$ dry tissue was decreased compared with previously determined values in intact controls.

Effect of glucocorticoids on colonic sodium absorption in adrenalectomized rats. Replacement of glucocorticoids in the absence of aldosterone was markedly effective in restoring proximal colon sodium absorption (Fig. 1). The $0.5-\mathrm{nmol}$ dose significantly increased sodium absorption $(P<0.05)$. The value of $4.5 \pm 0.5$ $\mu \mathrm{eq} / \mathrm{min}$ per $\mathrm{g}$ dry tissue was lower than that usually found in intact rats. The dose response curve was hyperbolic, with the greatest rate of increase occurring at the two lowest doses. With $10 \mathrm{nmol}$, sodium absorption reached $15.0 \pm 1.1 \mu \mathrm{eq} / \mathrm{min}$ per $\mathrm{g}$

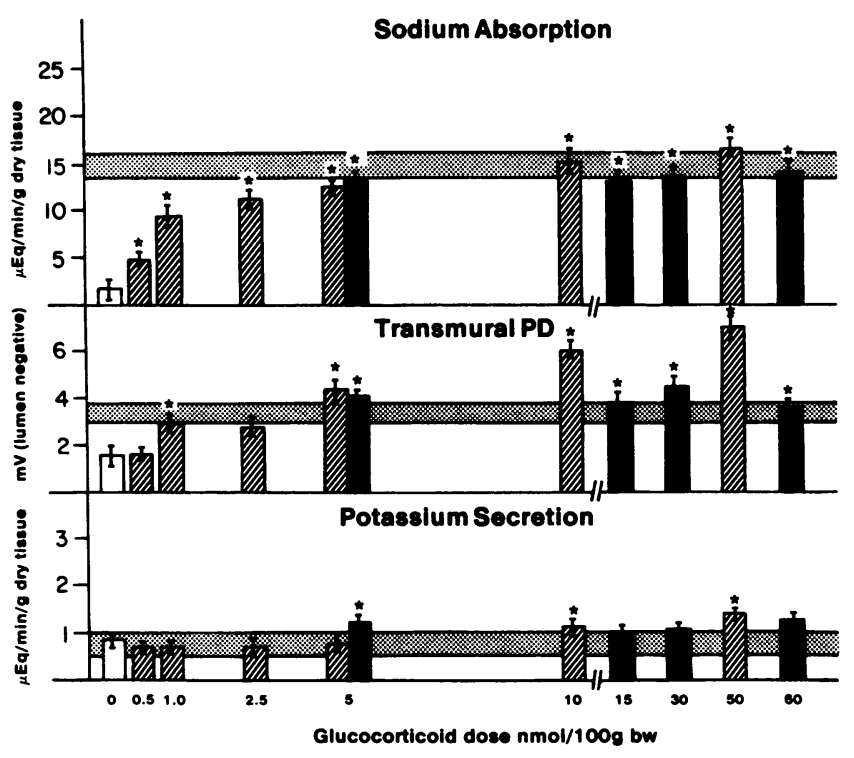

Figure 1. The effect of glucocorticoids on in vivo proximal colon net sodium absorption, transmural PD, and net potassium secretion in adrenalectomized rats. Values are the mean \pm SEM. Each group had a minimum of seven rats except for the highest dose of RU26988, which had six rats. (Stippled crossbars) Mean value \pm 2 SEM for 29 intact, untreated rats. (Open bars) Adrenalectomized rats. (Hatched bars) Rats treated with dexamethasone. (Solid bars) Rats treated with RU26988. *Significantly different from adrenalectomy alone. 


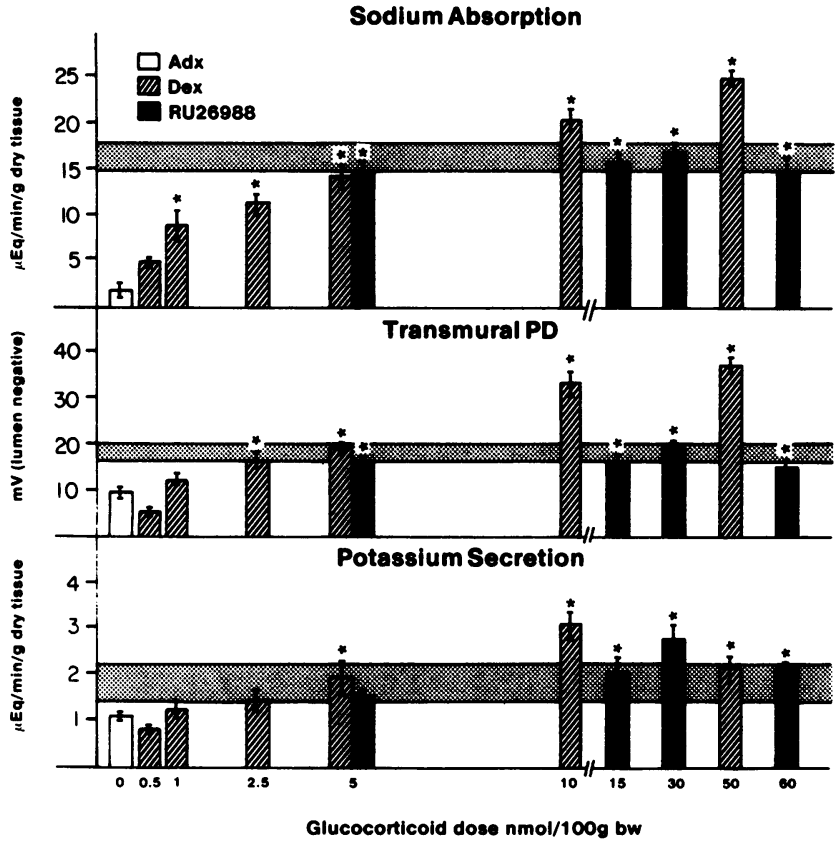

Figure 2. Effect of glucocorticoids on in vivo distal colon net sodium absorption, transmural PD, and net potassium secretion in adrenalectomized rats. Further details are given in Fig. 1.

dry tissue, a value similar to that found in intact animals $(P$ $<0.001$ compared with adrenalectomy alone). However, even with $50 \mathrm{nmol}$ of dexamethasone the sodium-absorptive rate was not significantly greater than that found in intact control rats. Water secretion changed to water absorption at the $0.5-\mathrm{nmol}$ dose, $11.1 \pm 2.2 \mu \mathrm{l} / \mathrm{min}$ per $\mathrm{g}$ dry tissue. The ratio of sodium absorption to water absorption was constant at $0.39 \mu \mathrm{eq} / \mu \mathrm{l}$.

In distal colon (Fig. 2), the 0.5 -nmol dose produced an almost identical increment in sodium absorption to $5.1 \pm 0.6 \mu \mathrm{eq} / \mathrm{min}$ per $\mathrm{g}$ dry tissue. Although this failed to reach statistical significance, all higher doses were significantly greater than adrenalectomy alone. The dose response curve was hyperbolic, with the greatest rate of increase occurring at lower doses, but the effect did not reach a plateau. The values found with the 10 - and 50nmol doses of $20.6 \pm 1.0$ and $25.1 \pm 0.7 \mu \mathrm{eq} / \mathrm{min}$ per g dry tissue were significantly higher than that normally found in intact controls $(P<0.05$ for the 10 -nmol dose). Water absorption also markedly increased, and from the 2.4- to 50-nmol doses the ratio of sodium absorption to water absorption ranged from $\mathbf{0 . 3 0}$ to $0.34 \mu \mathrm{eq} / \mu \mathrm{l}$.

Other investigators have postulated that this effect of dexamethasone on sodium absorption is only seen because the period after adrenalectomy is too short to reach an aldosterone-independent state of basal transport functions (20). Six rats were adrenalectomized and given no steroid replacement for $1 \mathrm{wk}$. During the $24 \mathrm{~h}$ before the experiment, they were given the 5nmol dose of dexamethasone as in the 24-h adrenalectomy protocol. After $1 \mathrm{wk}$ of no exposure to adrenal steroids, the response to dexamethasone was indistinguishable from that of the more acute protocol $(P=N S)$. Sodium absorption was $13.4 \pm 0.9$ in proximal colon and $15.7 \pm 0.8 \mu \mathrm{eq} / \mathrm{min}$ per $\mathrm{g}$ dry tissue in distal colon. Transmural $P D$ was $3.4 \pm 0.4$ and $16.4 \pm 0.9 \mathrm{mV}$ in proximal and distal colon, respectively.

After subcutaneous injection of dexamethasone, there is rapid steroid absorption. Plasma levels remain relatively constant for
$2 \mathrm{~h}$ due to continued absorption from the injection site. For example, with the 10-nmol dose, mean plasma levels were $5.7 \pm 0.7 \times 10^{-8} \mathrm{M}, 5.9 \pm 0.4 \times 10^{-8} \mathrm{M}$, and $5.3 \pm 0.4 \times 10^{-8} \mathrm{M}$ at $0.5,1$, and $2 \mathrm{~h}$ after injection. Levels decreased more rapidly after $2 \mathrm{~h}$ and fell to $62 \%$ of peak values by $3 \mathrm{~h}$. Plasma levels for the first two time periods are linearly related to the injected molar dose (Fig. $3 A ; P<0.001$ ).

Because the plasma levels remained constant over this period and steroids diffuse readily into cells, the intracellular steroid concentration should be similar to that measured in plasma. The reported $K_{d} \mathrm{~s}$ for the glucocorticoid receptor are $3.7 \times 10^{-9}$ $M$ in rat proximal colon and 5.8-6.2 $\times 10^{-9} \mathrm{M}$ in rat distal colon $(10,12)$. Using values for the $K_{\mathrm{d}}$ and $B_{\max }$ we had previously obtained for proximal and distal colon, we estimated the percent occupancy of the glucocorticoid receptor from the plasma value at each dose injected (Fig. $3 B$ ). The calculated maximum percent occupancy in proximal colon ranged from $36 \%$ at the lowest

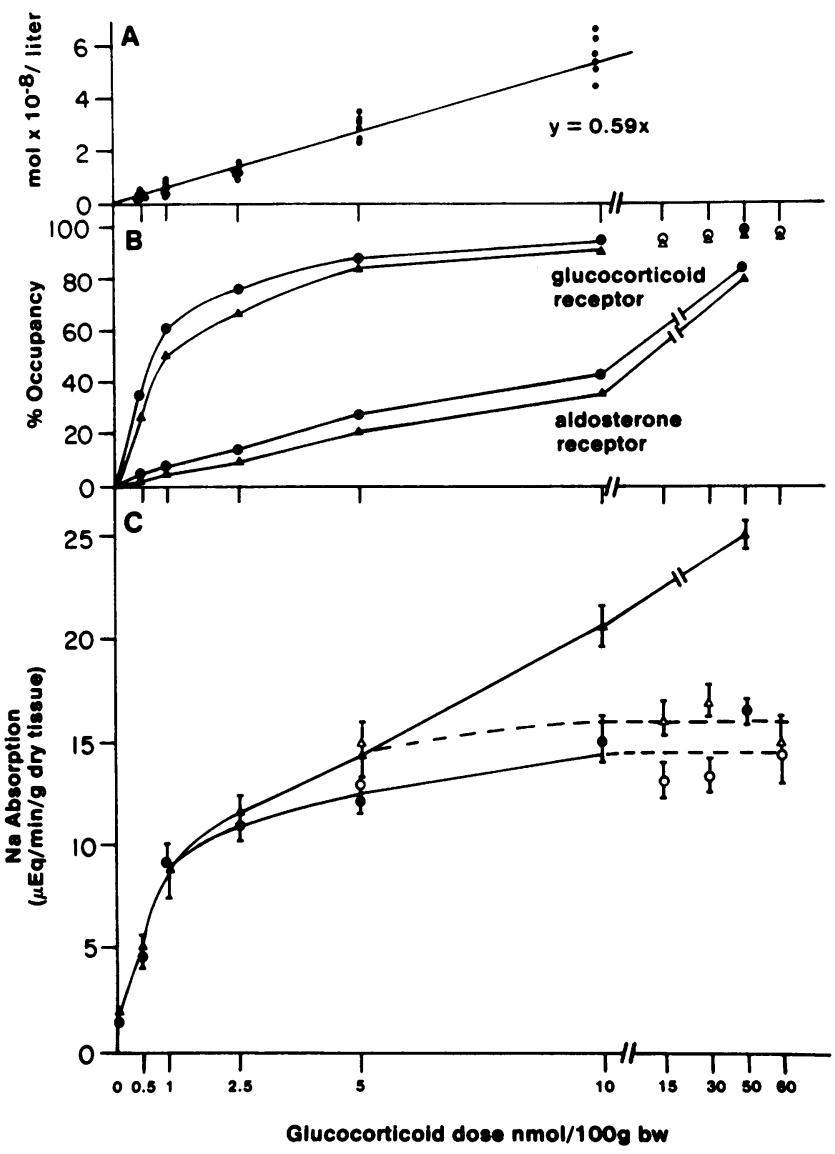

Figure 3. Correlation of glucocorticoid-induced sodium absorption with plasma concentrations of dexamethasone and estimated percent receptor occupancy in proximal and distal colon. $(A)$ Linear regression line for plasma concentrations of dexamethasone $(y)$ plotted against $\mathrm{nmol} / 100 \mathrm{~g}$ body wt of dexamethasone injected $(x)$. Dots represent individual plasma values. $(B)$ Percentage glucocorticoid receptor occupancy (upper lines) and aldosterone receptor occupancy (lower lines) in proximal and distal colon. Values were determined from plasma levels of steroids illustrated in $A$. Plasma level for the 50-nmol dose, $47 \pm 4 \times 10^{-8} \mathrm{M}$, is not illustrated. Details of the calculations are given in the text. $(C)$ Dose response curves of sodium absorption as a function of the nmol dose of steroid injected. Dexamethasone values for

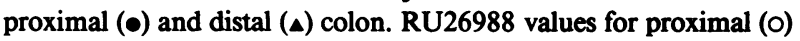
and distal $(\Delta)$ colon. 
dose to $99 \%$ at the highest dose. The calculated occupancy in distal colon ranged from 26 to $99 \%$ (Fig. $3 \mathrm{~B}$ ). The rate of sodium absorption produced by increasing doses of dexamethasone (Fig. $3 C$ ) closely paralleled the calculated increase in percent receptor occupancy except at the highest doses of dexamethasone. This suggests that the actions of dexamethasone are effected by binding to the glucocorticoid receptor.

Glucocorticoid occupancy of aldosterone receptors can also be estimated from aldosterone receptors' $K_{d}, B_{\max }$, and the relative affinity of glucocorticoids for the aldosterone receptor (25, 26). We have recently reported these data for both proximal and distal colon. The aldosterone receptor has a $K_{d}$ of 4.1 and 4.2 $\mathrm{nM}$ and a $B_{\max }$ of $6.5 \times 10^{-14}$ and $15.6 \times 10^{-14} \mathrm{~mol} / \mathrm{mg}$ cytosol protein in proximal and distal colon, respectively (11). The $K_{\mathrm{d}} \mathrm{s}$ and $B_{\max }$ are remarkably close to values recently reported for human colon, where the $K_{\mathrm{d}}$ of ascending colon was $3.8 \mathrm{nM}$ and $B_{\max } 7.6 \times 10^{-14} \mathrm{~mol} / \mathrm{mg}$ protein. Human sigmoid colon binding was $14 \times 10^{-14} \mathrm{~mol} / \mathrm{mg}$ protein (32). In proximal colon, which has the lower aldosterone receptor number, the estimated occupancy of the aldosterone receptor by dexamethasone ranged from $2.7 \%$ at the lowest dose to $84 \%$ at the highest dose (Fig. 3 $B)$. In distal colon, occupancy ranged from 1.9 to $81 \%$. At the two highest doses of dexamethasone used, the estimated percent occupancy of the aldosterone receptor is at a level where an effect mediated via aldosterone-induced pathways would be expected $(13,29)$.

To determine if the changes at the highest dose should be attributed to glucocorticoid-induced pathways or to aldosteroneinduced pathways, the perfusion studies were repeated in adrenalectomized rats treated with the synthetic glucocorticoid, RU26988. The 5-nmol dose was chosen to compare the potency of dexamethasone and RU26988. In proximal colon, the rate of sodium absorption produced by RU26988 was identical to that produced by an equimolar dose of dexamethasone, 12.8 \pm 0.7 and $12.2 \pm 0.6 \mu \mathrm{eq} / \mathrm{min}$ per $\mathrm{g}$ dry tissue, respectively (Fig. 1). Increasing the dose of RU26988 to doses predicted to approach saturation of the glucocorticoid receptor produced small increases in sodium absorption to a maximum level of $14.4 \pm 1.4$ $\mu \mathrm{eq} / \mathrm{min}$ per $\mathrm{g}$ dry tissue with $60 \mathrm{nmol}$ of RU26988 suggesting pure glucocorticoid-induced sodium absorption is saturable in proximal colon (Fig. $3 \mathrm{C}$ ). This value is identical to the value found in intact control rats of $14.8 \pm 0.6 \mu \mathrm{eq} / \mathrm{min}$ per $\mathrm{g}$ dry tissue. It differed slightly from those obtained with higher doses of dexamethasone which, at the highest dose, increased sodium absorption to $16.5 \pm 0.4 \mu \mathrm{eq} / \mathrm{min}$ per $\mathrm{g}$ dry tissue (15\% higher than found with RU26988, $P=\mathrm{NS}$ ). Thus, most of the increase in proximal colon sodium absorption produced by dexamethasone even at the highest doses could be mediated by a glucocorticoid-specific mechanism.

In distal colon, $5 \mathrm{nmol}$ of RU26988 produced a marked increase in sodium absorption to $14.8 \pm 0.8 \mu \mathrm{eq} / \mathrm{min}$ per $\mathrm{g}$ dry tissue, identical to the value of $14.5 \pm 1.3$ achieved with equimolar doses of dexamethasone. Increasing the dose of RU26988 to levels that saturate the glucocorticoid receptor increased sodium absorption to as high as $16.9 \pm 0.7 \mu \mathrm{eq} / \mathrm{min}$ per $\mathrm{g}$ dry tissue at the $30 \mathrm{nmol}$ dose. As in proximal colon, treatment with doses estimated to produce 94-99\% occupancy of the glucocorticoid receptor also appeared to saturate the glucocorticoid-induced sodium absorptive mechanism. The levels of sodium absorption were similar to those found in intact control rats (Fig. 2). These results are distinct from those produced by increasing doses of dexamethasone, where a plateau in sodium absorption was not achieved. The highest sodium-absorptive rate found with dexamethasone of $25.1 \pm 0.7 \mu \mathrm{eq} / \mathrm{min}$ per $\mathrm{g}$ dry tissue was $50 \%$ greater than the highest value found with RU26988 ( $P<0.001$ compared to each RU26988 group). The difference in response between dexamethasone and RU26988 at high doses is probably due to dexamethasone stimulating an aldosterone-induced pathway when $35-80 \%$ of aldosterone receptors are occupied (Fig. 3, $B$ and $C$ ). The difference in response of proximal and distal colon to doses of dexamethasone that produce similar percent occupancy of the aldosterone receptor can probably be explained by the markedly greater number of aldosterone receptors in distal colon ( $240 \%$ of the number in proximal colon).

Because in both segments of colon pure glucocorticoid-mediated increases in sodium absorption appear to be saturable, the kinetics of the colonic increase in sodium absorption can be analyzed. The data were transformed into an Eadie-Hofstee plot using moles of injected dexamethasone and RU26988. The points for the two highest doses of dexamethasone were excluded in distal colon because of the probability of induction of aldosterone-induced pathways. The maximum sodium absorption for proximal colon $\left(J_{\mathrm{Na}} \mathrm{max}\right)$ is $14.4 \pm 0.8 \mu \mathrm{eq} / \mathrm{min}$ per $\mathrm{g}$ dry tissue, and the Michaelis constant $\left(K_{\mathrm{m}}\right)$ is $8.0 \times 10^{-10} \mathrm{~mol} / 100 \mathrm{~g}$ body wt. For distal colon, the $J_{\mathrm{Na}} \max$ is $15 \mu \mathrm{eq} / \mathrm{min}$ per $\mathrm{g}$ dry tissue and the $K_{\mathrm{m}}$ is $9.8 \times 10^{-10} \mathrm{~mol} / 100 \mathrm{~g}$ body wt. To relate changes in sodium absorption to circulating glucocorticoid levels, EadieHofstee plots were determined using the steroid plasma levels obtained (Fig. 4). This gave the same $J_{\mathrm{Na}} \max$ for each segment. The $K_{\mathrm{m}}$ in proximal colon was $4.2 \pm 0.5 \mathrm{nmol} /$ liter and in distal colon was $4.6 \pm 0.4 \mathrm{nmol} /$ liter. The saturation of the pure glucocorticoid-induced transport in both segments of colon and the similarity of the $J_{\mathrm{Na}} \max$ and $K_{\mathrm{m}}$ in both segments $(P=\mathrm{NS})$, suggests the sodium transport pathway stimulated is the same in proximal and distal colon.

The $K_{\mathrm{m}}$ for a reaction should be a reflection of the receptor $K_{d}$ if the reaction results from receptor-mediated pathways (33). The ratio of $K_{\mathrm{m}}$ to $K_{\mathrm{d}}$ in proximal colon was 1.1:1 and in distal colon 0.8:1 using plasma values for the $K_{\mathrm{m}}$. These $K_{\mathrm{m}} \mathrm{s}$ would give an estimated receptor occupancy of $53 \%$ for proximal colon and $44 \%$ for distal colon. Considering the accuracy of the estimate of both the $K_{\mathrm{m}}$ and $K_{\mathrm{d}}$, the $K_{\mathrm{m}}$ for glucocorticoid-induced sodium

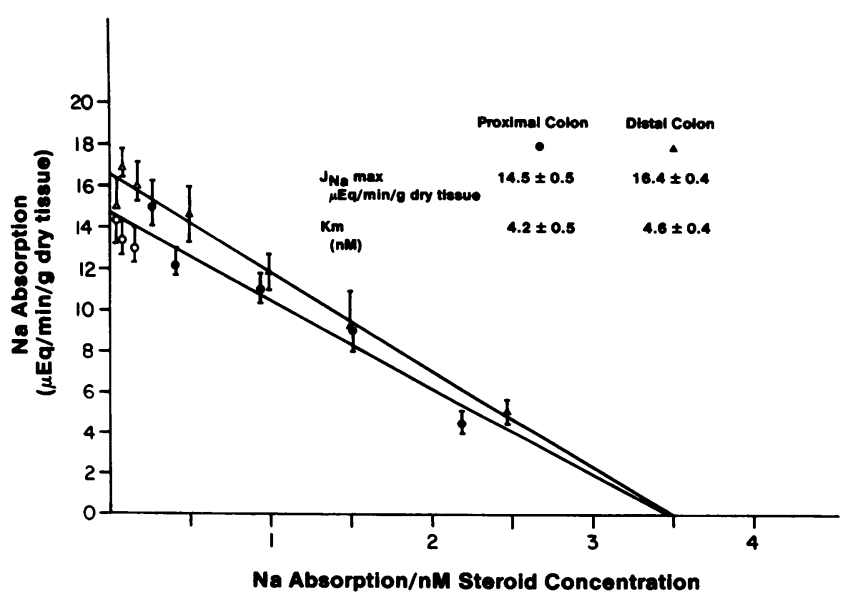

Figure 4. Eadie-Hofstee plot of data shown in Fig. 3. Sodium absorption $(y)$ is plotted against sodium absorption/plasma concentration of steroid for both proximal and distal colon. Symbols are the same as in Fig. 3 for dexamethasone and RU26988 data. Values shown are the mean \pm SEM for sodium absorption at each dose of steroid used. 
absorption is quite similar to the colonic glucocorticoid receptor $K_{d}$.

Effect of glucocorticoids on colonic transmural potential difference. The proximal colon of intact rats is characterized by a low transmural PD, $-3.4 \pm 0.2 \mathrm{mV}$ (Fig. 1), which may not be generated by active sodium absorption (15, 19, 31, 34-36). However, it does decrease significantly with adrenalectomy. Glucocorticoids increase the negativity of the transmural PD, but at lower doses the effect on transmural PD is less striking than the effect on sodium adsorption. The 5-nmol doses of RU26988 and dexamethasone produced equivalent increases in transmural PD, $-4.0 \pm 0.3$ and $-4.3 \pm 0.4 \mathrm{mV}$, respectively. Only the two highest doses of dexamethasone clearly increased the transmural PD to levels higher than that found in control rats, whereas receptor-saturating doses of RU26988 increased the transmural PD to, but not above, control values $(P<0.001$ RU26988 to dexamethasone).

The lumen negative transmural PD of the distal colon is high in intact rats compared with the value found in proximal colon, $-18.2 \pm 0.7 \mathrm{mV}$, and is also halved by adrenalectomy (Fig. 2). The pattern of glucocorticoid effect on transmural PD in distal colon was similar to that found in proximal colon. In this segment the effect lagged behind the effect on sodium absorption becoming significantly greater than adrenalectomy alone at the $2.5 \mathrm{nmol}$ dose $(P<0.01)$. The highest doses of dexamethasone hyperpolarized the transmural PD whereas saturating doses of RU26988 restored the transmural PD only to normal levels. The results in both proximal and distal colon suggest that hyperpolarization of these epithelia by dexamethasone may be mediated via an aldosterone effector pathway.

It has not been determined if the increase in transmural PD induced by low doses of glucocorticoids is generated by the change in sodium absorption. In both segments using individual experimental values, a weak correlation was found between glucocorticoid-induced sodium absorption and changes in transmural PD (proximal colon, $r=0.555, P<0.001$; distal colon, $r=0.553, P<0.001$ ).

Effect of glucocorticoids on colonic potassium secretion. It is not clear that low doses of glucocorticoids have a specific effect on proximal colon potassium secretion. Potassium secretion was not different from control values 24-h after adrenalectomy (Fig. 1) and did not clearly increase with small doses of dexamethasone or large doses of RU26988. Potassium secretion was elevated above normal as well as adrenalectomy values with the 50-nmol dose of dexamethasone $(P<0.05)$. In distal colon (Fig. 2), where potassium secretion in adrenalectomized animals was decreased below intact control values of $1.8 \pm 0.7 \mu \mathrm{eq} / \mathrm{min}$ per $\mathrm{g}$ dry tissue, glucocorticoids did increase potassium secretion. However, this effect was only apparent and significant at doses of steroids which increased the transmural PD back to or above the normal range. The rates of potassium secretion achieved with the saturating doses of RU26988 were not greater than that found in control rats. However, higher doses of dexamethasone also did not consistently increase the level of potassium secretion above normal.

The luminal negativity of the colon, which was increased by glucocorticoids, should act as a passive driving force to increase potassium secretion $(15,21,31,37-42)$. However using individual experimental values for transmural PD and rate of potassium secretion, we found only weak direct correlations between these two variables in proximal colon $(r=0.425, P$ $<0.001)$ and distal colon $(r=0.573, P<0.001)$.

Time course of glucocorticoid-induced transport changes. It has not been determined how long the effects of low-dose glucocorticoids on transport will persist. To determine if the effects were prolonged or additive, adrenalectomized animals were treated with dexamethasone at a dose of 1-10 nmol as in the previous experiments except that they did not receive the final dose before the perfusion study. Even in the group receiving the highest dose (10 nmol) sodium absorption in distal colon of $-0.39 \pm 0.15 \mu \mathrm{eq} / \mathrm{min}$ per $\mathrm{g}$ dry tissue was not different from the values found after adrenalectomy. Results were identical in the proximal colon and showed no variation with previous dose administered. For all 16 rats studied, sodium absorption was $0.23 \pm 0.34$ and $0.30 \pm 0.5 \mu \mathrm{eq} / \mathrm{min}$ per $\mathrm{g}$ dry tissue in proximal and distal colon, respectively. Transmural PD and potassium secretion were also indistinguishable from values obtained in non-steroid-treated animals in all groups in both segments. These results suggest that loss of glucocorticoid effect must be fairly rapid after steroid clearance.

The time of onset of glucocorticoid-induced transport was determined in vivo (Fig. 5). After measurement of basal transport, a total dose of $10 \mathrm{nmol}$ of dexamethasone was injected intravenously ( $3.3 \mathrm{nmol} / 100 \mathrm{~g}$ body $\mathrm{wt}$ for a $300-\mathrm{g} \mathrm{rat})$. In adrenalectomized rats with no steroid replacement, transport parameters do not increase with time. The response to dexamethasone was marked and brisk. In proximal colon, the sodium absorption rate in effluent collected between 0 and 30 min was $6.5 \pm 1.0$, compared to a rate of $-0.5 \pm 0.77 \mu \mathrm{eq} / \mathrm{min}$ per $\mathrm{g}$ dry tissue before steroid injection $(P<0.005)$. Thus the onset of dexamethasone effect occurred within $30 \mathrm{~min}$. Between $30 \mathrm{~min}$ and $1 \mathrm{~h}$, the rate of sodium absorption was $9.3 \pm 1.1 \mu \mathrm{eq} / \mathrm{min}$ per $\mathbf{g}$ dry tissue. In adrenalectomized rats receiving no steroid, the rate of sodium absorption at this time period was $0.16 \pm 0.6$
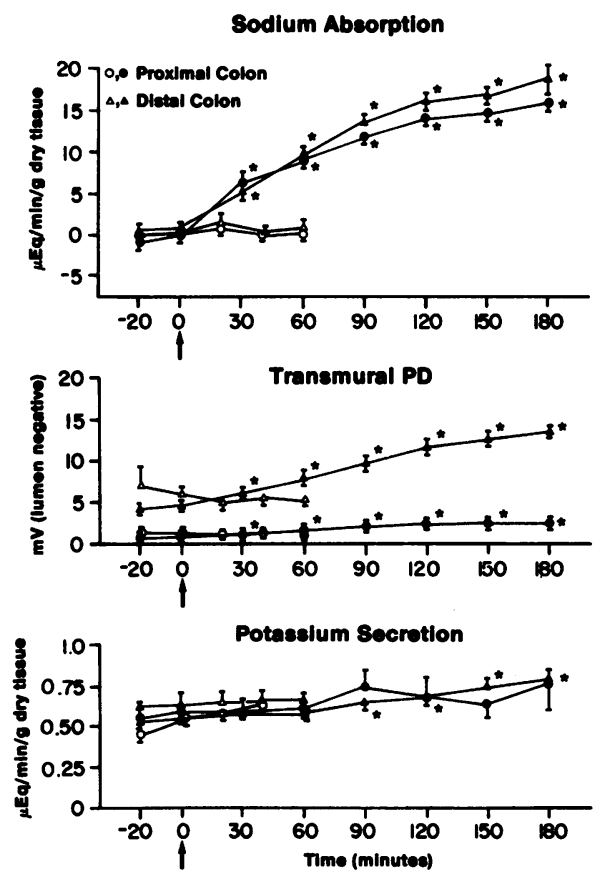

Figure 5. Time course of proximal and distal colon transport changes induced by acute intravenous injection of dexamethasone. Transport was measured before and for six 30-min periods after injection of 10 nmol of dexamethasone (arrow). (Solid symbols) Values from seven adrenalectomized rats injected with dexamethasone. (Open symbols) From 26 historical adrenalectomized time controls. 
$\mu \mathrm{eq} / \mathrm{min}$ per $\mathrm{g}$ dry tissue $(P<0.001)$. Sodium absorption continued to increase for $3 \mathrm{~h}$ postinjection, although between 90 and 120 min the rate was already $87 \%$ of the final value, suggesting a plateauing of the effect. Water flux changed from net secretion to net absorption by $30 \mathrm{~min}(P<0.005)$ and also continued to increase for $3 \mathrm{~h}$. The increase in transmural PD became significant at $1 \mathrm{~h}$ postinjection $(P<0.01)$ and plateaued between 2 and $3 \mathrm{~h}$ at a value $285 \%$ greater than adrenalectomy alone. Potassium secretion did not increase significantly in this interval.

In distal colon, acute injection of dexamethasone resulted in a marked increase in sodium absorption between 0 and $\mathbf{3 0}$ min, from $0.97 \pm 0.51$ to $5.2 \pm 1.1 \mu \mathrm{eq} / \mathrm{min}$ per $\mathrm{g}$ dry tissue $(P$ $<0.02$ ). Between $30 \mathrm{~min}$ and $1 \mathrm{~h}$ after steroid injection, sodium absorption was $9.9 \pm 0.8$ compared with $1.0 \pm 0.8 \mu \mathrm{eq} / \mathrm{min}$ per $\mathrm{g}$ dry tissue in adrenalectomized rats not receiving steroid $(P$ $<0.001$ ). Sodium absorption continued to rise to $18.7 \pm 1.7 \mu \mathrm{eq} /$ min per $\mathrm{g}$ dry tissue by the end of $3 \mathrm{~h}$, with $86 \%$ of this increase also occurring before $2 \mathrm{~h}$. There was a parallel increase in water absorption. The transmural PD also increased by $30 \mathrm{~min}$ and continued to increase for $3 \mathrm{~h}$ but reached $80 \%$ of the 3-h value by $2 \mathrm{~h}$. Potassium secretion was not significantly increased until 90 minutes after injection of dexamethasone. The maximal value obtained was only $34 \%$ greater than the adrenalectomy value.

\section{Discussion}

Since the original descriptions of colonic glucocorticoid-induced cation transport, several studies have described the effects of this steroid on in vivo and in vitro colon transport $(1,10,13,17$, $18,20,21,43,44)$. The results have not been uniform because of variability in the endogenous steroid status of the animal and the use of doses of glucocorticoids which even when claimed to be physiologic were probably pharmacologic. The few attempts to characterize a physiologic response to glucocorticoids have been carried out in vitro $(13,17)$.

Adrenalectomized rats were used in this study to eliminate variability in endogenous steroid production $(26,45,46)$. Plasma aldosterone levels of 5 to $10 \mathrm{ng} / \mathrm{dl}$ increase transmural PD to 20-30 mV in adrenalectomized rats (47). With anesthesia and intestinal perfusion in intact rats aldosterone levels rise to 63$119 \mathrm{ng} / \mathrm{dl}$ accompanied by marked increases in distal colon transmural PD (26). Corticosterone levels at least double under these stimuli. Maintenance of similar corticosterone levels is associated with increases in transmural PD in adrenalectomized rats (45). Consequently, endogenous adrenal steroids must be removed to study the effect of small doses of glucocorticoid. The steroid was administered in subcutaneous boluses, which gives fluctuation of circulating hormone levels. Because the rat has a diurnal variation in corticosterone levels from 3 to $21 \mu \mathrm{g} / \mathrm{dl}$, this method of administration may be more physiologic than maintenance of a constant plasma level (46).

Supraphysiologic doses of glucocorticoids increase sodium and water absorption, potassium secretion, and transmural PD in colon in vivo and in vitro. How much of this effect is due to crossover binding to the aldosterone receptor is not established. Because these transport changes are present in jejunum and ileum, which are not universally recognized aldosterone target sites, and because the effect is not inhibitable by spironolactone, an aldosterone-independent mechanism is suggested $(2,3,43$, 47-49). In proximal colon, ileum, and jejunum, the major in- crease in sodium absorption and short-circuit current produced by glucocorticoids is amiloride resistant, a finding uncharacteristic for an aldosterone-induced response $(2,8,36,49)$. In distal colon, amiloride-resistant transport may be induced with low doses or concentrations of dexamethasone and amiloride-inhibitable transport induced at doses of dexamethasone greater than the $10 \mathrm{nmol}$ dose used in this study $(2,3,5,7,8,17,18)$. Wills reported that the dose of dexamethasone required to produce $50 \%$ amiloride-sensitive short-circuit current in rat distal colon is $3 \mu \mathrm{g} / 100 \mathrm{~g}$ body wt per $\mathrm{h}(72 \mu \mathrm{g} / 100 \mathrm{~g}$ body wt per d), a dose exceeding the highest dose $(50 \mathrm{nmol})$ used in this study by $50 \%(8)$

In vivo dose response curves of colonic epithelial transport to glucocorticoids have not been previously reported. The marked increase in sodium absorption with the lowest dose of dexamethasone and further increases of transport with increasing doses argue that this is an exquisitely sensitive physiologic response. If sodium absorption were mediated via glucocorticoid receptors, a response would be expected at a plasma concentration that would produce significant occupancy of the glucocorticoid receptor $(29,33)$. This was indeed the observation in this study. In both proximal and distal colon, increases in sodium absorption occurred with plasma concentrations below the in vitro $K_{d}$ of the colonic receptor, and the response appeared to saturate at plasma levels of glucocorticoids that should approach saturation of the receptor. The $K_{\mathrm{m}}$ of the response is nearly the same as the $K_{d}$ of the receptor, suggesting a close correlation between glucocorticoid receptor occupancy and physiologic response. The marked response to low glucocorticoid concentrations has been reported in adrenalectomized rat and rabbit distal colon in vitro, where acute exposure to similar concentrations of dexamethasone, $1 \times 10^{-8} \mathrm{M}$, maximally stimulates shortcircuit current in rat (17) and increases short-circuit current in rabbit by $82 \%$ (13).

Because dexamethasone can occupy mineralocorticoid receptors and is potentially a mineralocorticoid agonist, separation of glucocorticoid receptor from aldosterone receptor-mediated effects has been difficult. Two lines of evidence suggest the major effect on sodium absorption observed in this study does not involve significant stimulation of aldosterone-induced pathways. In both proximal and distal colon only the two highest doses produced significant occupancy of the aldosterone receptor. Predicted occupancy at the $K_{\mathrm{m}}$ of the response is negligible (5\% in proximal colon, $4 \%$ in distal colon). In rabbit distal colon, $13 \%$ occupancy of aldosterone receptors by aldosterone itself does not significantly increase short-circuit current (13). In toad bladder, a fractional occupancy of aldosterone receptors by aldosterone of $<40 \%$ also does not significantly increase sodium absorption (29). Thus, unless dexamethasone is a far more potent aldosterone receptor agonist than aldosterone, it is unlikely that dexamethasone is primarily stimulating aldosterone-induced transport pathways.

The studies with RU26988 provide evidence to confirm these conclusions. Because RU26988 does not bind significantly to aldosterone receptors, the maximal level of RU26988-induced transport should reflect saturation of glucocorticoid receptormediated transport pathways. Further increases in transport with higher doses of dexamethasone could represent transport via aldosterone-induced pathways. Only in distal colon, which contains a much greater number of aldosterone receptors, were such increases found but only at the highest doses of dexamethasone (35\% or greater occupancy of aldosterone receptors) were these 
increases predicted. This suggests that in studies employing higher doses than those used in this study dexamethasone could be predominantly effecting aldosterone-induced pathways. Because RU26988 and dexamethasone produce quantitatively similar transport changes in proximal colon with occupancy of $>90 \%$ of glucocorticoid receptors, it is likely that both glucocorticoids are maximally stimulating the same pathway.

It is possible that the plateau seen with RU26988 occurs because RU26988 is a weaker glucocorticoid agonist than dexamethasone, as has been reported for some other glucocorticoidmediated events (23). However, $5 \mathrm{nmol}$ of both RU26988 and dexamethasone produced the same increase in sodium absorption in both segments, and in proximal colon no difference in potency was demonstrable at the highest doses of the two steroids. These data argue against that explanation. Receptor occupancy, calculated by assuming kinetics of distribution for RU26988 similar to that of dexamethasone, indicates that glucocorticoid receptor occupancy at the three highest doses should vary only between 94 and 99\% as saturation is approached (Fig. 3 B). Thus, apparent saturation of the physiologic response corresponds to predicted saturation of the receptor by RU26988.

Analysis of the kinetics of the changes in sodium absorption suggests low-dose glucocorticoids are stimulating the same pathway of sodium absorption in proximal and distal colon. The rate of sodium absorption at each dose from 0.5 to $5 \mathrm{nmol}$ (Fig. $3 \mathrm{C}$ ), the maximal rate of sodium absorption, and the $K_{\mathrm{m}}$ are similar in the two segments. With acute intravenous infusion of dexamethasone, the rate of rise of sodium absorption and the levels of sodium absorption achieved are similar. Thus, glucocorticoids should effect transport by a mechanism common to both segments. It is unlikely that the mechanism involves the amiloride-sensitive, sodium-conductive channel affected by aldosterone. Only minimal amiloride-sensitive sodium absorption has been demonstrated in proximal colon of control, aldosteronetreated, or sodium-deficient animals, and it has been concluded that the proximal colon has limited amiloride-sensitive sodium carriers $(2,8,14-16,36,50,51)$. The doses of glucocorticoid that increase sodium absorption are much lower than those that produce amiloride-sensitive sodium absorption, and the onset appears too rapid for that system (8). The lag time for induction of the amiloride channel in distal colon of rats treated with aldosterone in vivo is $4 \mathrm{~h} \mathrm{(8)}$. In this study, sodium absorption increases before $30 \mathrm{~min}$ with acute injection of dexamethasone. Finally, at these doses of dexamethasone we have demonstrated that colonic sodium absorption is not inhibitable by $10^{-4} \mathrm{M}$ amiloride, and at similar in vitro concentrations of dexamethasone the fraction of distal colon short-circuit current (Isc) inhibitable by $10^{-3} \mathrm{M}$ amiloride did not increase $(17,18)$. Because the specific glucocorticoid response is to restore sodium absorption to (but not above) normal levels in adrenalectomized rats, it is possible that glucocorticoids are primarily stimulating the electroneutral sodium chloride absorptive system, the only system demonstrated to be present in both segments, and the principle mechanism of sodium absorption in normal rats.

The effect of low-dose glucocorticoids is distinct from that produced in distal colon by doses of glucocorticoid greater than necessary to saturate the glucocorticoid receptor. Chronic exposure to supraphysiologic doses of dexamethasone consistently induces amiloride-sensitive sodium absorption in distal colon, suggesting induction of a second effector pathway (2, 3, 5-9). Whether this represents stimulation via occupancy of aldosterone receptors or is a true glucocorticoid effect is unresolved. Our data suggest that saturation of the aldosterone receptor by glucocorticoids would be expected at the doses used in those studies. However, this induction does not necessarily have to be initiated by binding to the aldosterone receptor but could involve posttranslational stimulation of the aldosterone effector pathway through a non-receptor-mediated mechanism. This possibility must be raised because spironolactone may produce minimal or no inhibition of sodium absorption in rats with dexamethasone-induced, amiloride-sensitive sodium absorption (3). The necessity for supersaturating doses also suggests this pathway may not be receptor mediated (52).

Time-course measurements of glucocorticoid-induced transport changes had previously only been performed in vitro on adrenalectomized animals $(13,17)$. Glucocorticoids in vitro induce increases in short-circuit current only after 2-4 h, a period consistent with receptor-mediated new protein production. The in vivo effect is much more rapid, suggesting some mechanism other than new protein production may be involved in the very early part of the response. In this regard, one study using massive doses of dexamethasone demonstrated that colonic transport changes were only partially inhibitable by cycloheximide, in contrast to the results found with deoxycorticosterone (4). The response is also more rapid than reported for aldosterone-induced transport changes, whether measured in vivo or in vitro $(13,16$, $17,19)$. Although these findings suggest the effect is not entirely mediated by new protein synthesis, they do not imply that the effect is mediated by non-receptor pathways. In other systems, several glucocorticoid effects have been described which may be receptor-mediated but do not appear to result from new protein synthesis (53). Therefore, changes in colon transport may represent another such example.

An unexpected finding was the apparent rapid dissipation of glucocorticoid effect with complete return to baseline within 12-14 $\mathrm{h}$. These results are in direct contradistinction to those reported for pharmacologic doses of dexamethasone, where the peak effect on transmural PD occurs $24 \mathrm{~h}$ after administration (44). However, this finding may explain why some investigators have found that low intermittent doses of dexamethasone had no effect on sodium absorption when administered to adrenalectomized animals, because in neither of these reports was the timing of the dexamethasone dose specified $(20,21)$.

Physiologic doses of glucocorticoids have a significant effect on transmural PD in both proximal and distal colon of adrenalectomized rats. However, the specific glucocorticoid effect appears to be restoration of the transmural PD only to basal control levels, an effect that is distinct from the marked increases in luminal negativity seen with aldosterone or supersaturating doses of glucocorticoid. Extensive research has demonstrated that the marked increase in transmural PD of distal rat colon produced by aldosterone is generated by electrogenic sodium absorption (19, 21, 34-38, 54, 55). Evidence suggests high dose glucocorticoids produce their effect by a similar mechanism. The etiology of the negative transmural $\mathrm{PD}$ in rats receiving low doses of glucocorticoids and in intact, unstressed rats is not clear. In control rats, blockade of sodium-conductive channels leads to no alteration of apical, basolateral membrane or transepithelial PD $(5-8,16,17,55)$. It has also been demonstrated that dexamethasone can generate an amiloride-resistant transmural PD and short-circuit current $(2,8,17,18,21)$. Even with pharmacologic doses in in vitro experiments, dexamethasone appears to have a weaker effect on rat intestine electrical conductance than does aldosterone $(2,5,7)$. The nature of the ion movement 
generating the transmural PD and Isc with low-dose glucocorticoids cannot be determined from these experiments or from the available in vitro literature and thus remains uncertain. If the role of glucocorticoids is to maintain the basal mode of colonic transport then the increase in transmural PD could represent coupled electroneutral sodium chloride absorption with electrogenic anion secretion $(2,8)$. This is an unproven postulate but there are several reports that large doses of glucocorticoid stimulate intestinal electrogenic anion secretion with resultant increase in transmural PD and Isc (6, 47-49).

Adrenalectomy does not diminish potassium secretory rates in proximal colon, suggesting basal potassium secretion in this segment is not steroid dependent. In distal colon, adrenalectomy significantly decreases basal potassium secretion, and glucocorticoids restore the rate to normal. The increase in luminal negativity produced by glucocorticoids should enhance distal colon potassium secretion $(15,21,31,37-44)$ but in these experiments a strong direct correlation between these two variables was not found. However, when the transmural PD is nullified in vitro, pharmacologic doses of dexamethasone result in zero net potassium secretion (5). In that study, dexamethasone increased serosal-to-mucosal flux but did not diminish mucosal-to-serosal flux. In contrast, aldosterone increased secretion while decreasing absorption, resulting in a marked increase in net potassium secretion. Endogenous hyperaldosteronism increases potassium secretion sixfold in proximal colon (15). This is in direct contrast to the negligible effect of glucocorticoids on proximal potassium secretion. In both segments, aldosterone-induced potassium secretion has been demonstrated to be active $(15,38,56)$. Whether low doses of glucocorticoids can also induce active potassium secretion in the absence of binding to the aldosterone receptor remains unknown.

\section{Acknowledgments}

The criticism and advice of Ronald Tallarida, Department of Pharmacology, is greatly appreciated. RU26988 was the kind gift of Roussel UCLAF, Paris.

C. P. Bastl is an Established Investigator of the American Heart Association. This work was supported by Public Health Service grant AM27486 from the National Institute of Arthritis, Diabetes, and Digestive and Kidney Diseases.

\section{References}

1. Bastl, C. P., H. J. Binder, and J. P. Hayslett. 1980. Role of glucocorticoids and aldosterone in maintenance of colonic cation transport. Am. J. Physiol. 238:F181-F186.

2. Will, P. C., R. C. DeLisle, R. N. Cartright, and U. Hopfer. 1981. Induction of amiloride-sensitive sodium transport in the intestines by adrenal steroids. Proc. NY Acad. Sci. 372:64-80.

3. Charney, A. N., J. Wallach, S. Ceccarelli, M. Donowitz, and C. L. Costerbader. 1981. Effects of spironolactone and amiloride on corticosteroid-induced changes in colonic function. Am. J. Physiol. 241: G300-G305.

4. Charney, A. N., J. D. Wallach, M. Donowitz, and N. Johnstone. 1982. Effect of cycloheximide on corticosteroid-induced changes in colonic function. Am. J. Physiol. 243:G112-G116.

5. Foster, E. S., T. W. Zimmerman, J. P. Hayslett, and H. J. Binder. 1983. Corticosteroid alteration of active electrolyte transport in rat distal colon. Am. J. Physiol. 245:G668-G675.

6. Bridges, R. J., W. Rummel, and P. Wollenberg. 1984. Effects of vasopressin on electrolyte transport across isolated colon from normal and dexamethasone-treated rats. J. Physiol. (Lond.). 355:11-23.
7. Perrone, R. D., and S. L. Jenks. 1984. Suppression of coupled Na$\mathrm{Cl}$ absorption by aldosterone and dexamethasone in rat distal colon in vitro. Am. J. Physiol. 246:F785-F793.

8. Will, P. C., R. N. Cartright, R. C. DeLisle, J. G. Douglas, and U. Hopfer. 1985. Regulation of amiloride-sensitive electrogenic sodium transport in the rat colon by steroid hormones. Am. J. Physiol. 248: G124-G132.

9. Clauss, W., J. Dürr, E. Skadharege, and H. Hörnicke. 1985. Effects of aldosterone and dexamethasone on apical membrane properties and Na-transport of rabbit distal colon in vitro. Pfluegers Arch. Eur. J. Physiol. 403:186-192.

10. Bastl, C. P., C. A. Barnett, T. J. Schmidt, and G. Litwack. 1984. Glucocorticoid stimulation of sodium absorption in colon epithelia is mediated by corticosteroid IB receptor. J. Biol. Chem. 259:1186-1195.

11. Schulman, G., A. Miller, G. Litwack, and C. Bastl. 1986. Characterization of the unactivated and activated aldosterone receptor. $J$. Biol. Chem. 261:12102-12108.

12. Marusic, E. T., J. P. Hayslett, and H. J. Binder. 1981. Corticosteroid binding studies in cytosol of colonic mucosa of the rat. Am. J. Physiol. 240:G417-G423.

13. Marver, D. 1984. Assessment of mineralocorticoid activity in the rabbit colon. Am. J. Physiol. 246:F437-F446.

14. Fromm, M., and U. Hegel. 1978. Segmental heterogeneity of epithelial transport in rat large intestine. Pfluegers Arch. Eur. J. Physiol. 378:71-83.

15. Hirsch, D., P. Pace, H. J. Binder, and J. P. Hayslett. 1984. Evidence that aldosterone influences transport in target tissues by dissimilar mechanisms. Am. J. Physiol. 248:F507-F512.

16. Will, P. C., J. L. Lebowitz, and U. Hopfer. 1980. Induction of amiloride sensitive sodium transport in rat colon by mineralocorticoids. Am. J. Physiol. 238:F261-F268.

17. Jorkasky, D., M. Cox, and G. M. Feldman. 1985. Differential effects of aldosterone and dexamethasone on rat colon in vitro. Am. J. Physiol. 248:G424-G431.

18. Bastl, C. P., and V. Kapoor. 1982. Amiloride distinguishes glucocorticoid from aldosterone stimulated sodium transport. Clin. Res. $30: 2$ and 44la.

19. Edmonds, C. J., and J. C. Marriott. 1967. The effect of aldosterone and adrenalectomy on the electrical potential difference of rat colon and in the transport of sodium, potassium chloride and bicarbonate. J. Endocrinol. 39:517-531.

20. Horster, M., and A. Lückhoff. 1983. Aldosterone on sodium transport of rat distal colon in long-term adrenalectomy during acute and chronic substitution. J. Physiol. (Lond.). 340:503-511.

21. Edmonds, C. J. 1981. Amiloride sensitivity of the transepithelial electrical potential and of sodium and potassium transport in rat distal colon in vivo. J. Physiol. (Lond.). 313:547-559.

22. Dolman, D., and C. J. Edmonds. 1975. The effect of aldosterone and the renin-angiotensin system on sodium, potassium and chloride transport by proximal and distal rat colon in vivo. J. Physiol. (Lond.). 250:597-611.

23. Teutsch, G., G. Costerousse, R. Deraedt, J. Benzoni, M. Fortin, and D. Philibert. 1981. 17 $\alpha$-Alkynl-11B,17-dihydroxyandrostane derivitives: a new class of potent glucocorticoids. Steroids. 38:661-665.

24. Gomez-Sanchez, C. E., and E. P. Gomez-Sanchez. 1983. RU26988: a new tool for the study of the mineralocorticoid receptor. Endocrinology. 113:1004-1009.

25. Mogiulewsky, M., and J. P. Raymaud. 1980. Evidence for a specific mineralocorticoid receptor in rat pituitary and brain. J. Steroid Biochem. 12:309-313.

26. Fromm, M., W. Oelkers, and U. Hegel. 1983. Time course of aldosterone and corticosterone plasma levels, in rats during general anesthesia and abdominal surgery. Pfluegers Arch. Eur. J. Physiol. 399:249254.

27. Lan, N. C., B. Graham, F. C. Bartter, and J. D. Baxter. 1982. Binding of steroids to the mineralocorticoid receptors: implications for in vivo occupancy by glucocorticoids. J. Clin. Endocrinol. Metab. 54: 332-342. 
28. Warnock, D. G., and I. S. Edelman. 1978. Occupancy of aldosterone binding sites in rat kidney cytosol. Mol. Cell. Endocr. 12:221233.

29. Geering, K., M. Claire, H. P. Gaeggler, and B. C. Rossier. 1985. Receptor occupancy vs. induction of Na-K-ATPase and $\mathrm{Na}^{+}$transport by aldosterone. Am. J. Physiol. 248:C102-C108.

30. Claire, M., J. L. Steimer, M. E. Oblin, H. P. Gaeggeler, A. Venot, P. Cowal, and B. C. Rossier. 1985. Cytoplasmic and nuclear uptake of aldosterone in toad bladder: a mathematical modeling approach. Am. J. Physiol. 248:C88-C101.

31. Edmonds, C. J. 1967. Transport of potassium by the colon of normal and sodium-depleted rats. J. Physiol. (Lond.). 193:603-617.

32. Rafestin-Oblin, M. E., M. Lombes, J. B. Michel, A. Michaud, and M. Claire. 1984. Mineralocorticoid receptors in the epithelial cells of human colon and ileum. J. Steroid Biochem. 20:311-315.

33. Rousseau, G. G., J. D. Baxter, and G. M. Tomkins. 1972. Glucocorticoid receptors: relations between steroid binding and biological effects. J. Mol. Biol. 67:99-115.

34. Edmonds, C. J. 1967. The gradient of electrical potential difference and of sodium and potassium of the gut contents along the caecum and colon of normal and sodium-depleted rats. J. Physiol. (Lond.). 193:517588.

35. Edmonds, C. J., and J. Marriott. 1968. Factors influencing the electrical potential across the mucosa of rat colon. J. Physiol. (Lond.). 194:457-478.

36. Clauss, W., H. Schafer, I. Horch, and H. Hornicke. 1985. Segmental differences in electrical properties and $\mathrm{Na}$-transport of rabbit caecum, proximal and distal colon in vitro. Pfluegers Arch. Eur. J. Physiol. 403:278-282.

37. Rask-Madsen, J. 1974. Transepithelial ionic transport and electrocal polarization in the large bowel. Scand. J. Gastroenterol. 9:223229.

38. Smith, P. L., and R. D. McCabe. 1984. Mechanism and regulation of transcellular potassium transport by the colon. Am. J. Physiol. 247: G445-G456.

39. Frizzell, R. A., and S. G. Schultz. 1978. Effect of aldosterone on ion transport by rabbit colon in vitro. J. Membr. Biol. 39:1-26.

40. Hayslett, J. P., J. Haley, P. E. Pace, and H. J. Binder. 1982. Demonstration of net potassium absorption in mammalian colon. Am. J. Physiol. 242:G209-G214.

41. Yau, W. M., and G. M. Makhlouf. 1975. Comparison of transport mechanisms isolated ascending and descending rat colon. Am. J. Physiol. 228:191-195.
42. Frizzell, R. A., M. J. Koch, and S. G. Schultz. 1976. Ion transport by rabbit colon: I. Active and passive components. J. Membr. Biol. 27: 297-316.

43. Charney, A. N., M. D. Kinsey, L. Myers, R. A. Giannella, and R. E. Gots. 1975. $\mathrm{Na}^{+}-\mathrm{K}^{+}$activated, adenosine triphosphatase and intestinal electrolyte transport: effect of adrenal steroids. J. Clin. Invest. 56:653-660.

44. Binder, H. J. 1978. Effect of dexamethasone on electrolyte transport in the large intestine of the rat. Gastroenterology. 75:212-217.

45. Martin, R. S., W. J. Jones, and J. P. Hayslett. 1983. Animal model to study the effect of adrenal hormones on epithelial function. Kidney Int. 24:386-391.

46. D'Agostino, J., G. F. Vaeth, and S. J. Henning. 1982. Diurnal rhythm of total and free concentrations of serum corticosterone in the rat. Acta Endocrinol. 100:85-90.

47. Sellin, J. H., and M. Field. 1981. Physiologic and pharmacologic effects of glucocorticoids on ion transport across rabbit ileal mucosa in vitro. J. Clin. Invest. 67:770-778.

48. Yuan-Heng, T., R. A. Decker, W. G. Marnane, A. N. Charney, and M. Donowitz. 1981. Effects of methylprednisolone on electrolyte transport by in vitro rat ileum. Am. J. Physiol. 240:G365-G370.

49. Sellin, J. H., and R. C. DeSoignie. 1983. Methylprednisolone increases absorptive capacity of rabbit ileum in vitro. Am. J. Physiol. 245:G562-G567.

50. Will, P. C., R. N. Cartright, R. G. Groseclose, and U. Hopfer. 1985. Amiloride-sensitive salt and fluid absorption in small intestine of sodium-depleted rats. Am. J. Physiol. 248:G133-G141.

51. Sellin, J. H., and R. DeSoignie. 1984. Rabbit proximal colon: a distinct transport epithelium. Am. J. Physiol. 246:G603-G610.

52. Edelman, I. S. 1975. Mechanism of action of steroid hormones. J. Steroid Biochem. 6:147-159.

53. Firestone, G. L., F. Payvai, and K. R. Yamamoto. 1982. Glucocorticoid regulation of protein processing and compartmentalization. Nature (Lond.). 300:221-225.

54. Schultz, S. G., R. A. Frizzell, and H. W. Nellans. 1977. Active sodium transport and the electrophysiology of rabbit colon. J. Membr. Biol. 33:351-384.

55. Sandle, G. I., J. P. Hayslett, and H. J. Binder. 1984. Effect of chronic hyperaldosteronism on the electrophysiology of rat distal colon. Pfluegers Arch. Eur. J. Physiol. 401:22-26.

56. Foster, E. S., J. P. Hayslett, and H. J. Binder. 1984. Mechanism of active potassium absorption and secretion in the rat colon. Am. J. Physiol. 246:G611-G617. 